\title{
Color Research of Chinese Traditional Architecture in Song Dynasty*
}

\author{
Xiaoguang Wang \\ Nanjing City Vocational College \\ Nanjing Radio and Television University \\ Nanjing, China
}

\begin{abstract}
Song Dynasty is an important period in the development of Chinese architecture. In this period, the use of architectural color has a profound influence on the use of colors in Chinese traditional architecture. This thesis focuses on the investigation and analysis of the extant Taiyuan Jinci goddess hall and Longxing Temple, and studies the architectural color of the Chinese Song Dynasty from the social aesthetic trend and social thought, finds out the characteristics of the architectural color of the Song Dynasty, and reveals the development and change of the traditional architectural color.
\end{abstract}

Keywords-Song dynasty; architecture color; jinci goddess hall; longxing temple

\section{INTRODUCTION}

After the unification of the Central Plains and the southern regions of the Song Dynasty, although they were confronted with Liao and Jin, they were weaker in military affairs and adopted a policy of compromise and concessions. However, there was a great development in the economy, handicraft industry and agriculture, and the continuous progress of science and technology.

Due to the development of production and technological progress, the architecture has been developed and made some achievements. In addition to the building of palaces, temples and towers, a large number of shops and houses have been built in the city. The colors of the buildings have been more clearly classified and stipulated, and the most complete Chinese code of construction, "Yin Zao Fa Shi" (The Rules of Architecture), has been issued. The rules laid down in the Song Dynasty showed that the building had already had a high level of standardization and stereotype. There are different types of colored paintings on the decoration of buildings. Many kinds of doors and windows are decorated together, forming a gentle, smart and beautiful architectural style.

\section{THE SONG DYNASTY RELICS OF TAIYUAN JINCI GODDESS HALL}

Jinci goddess hall, the core of the Jinci temple in Taiyuan,

*This paper is a series of achievements in the research project of philosophy and sociology in Jiangsu universities. Project: Color research of Chinese traditional architecture under the background of "China dream". Project approval number: 2015SJD329
Shanxi Province, was built in the Northern Song Dynasty (1023-1032 AD), and rebuilt in the year of the Chongning (1102-1106 AD). It is the representative work of the architectural palace in the Song Dynasty. It is also the oldest existing wooden structure in the jinci of Song Dynasty in "Fig. 1".

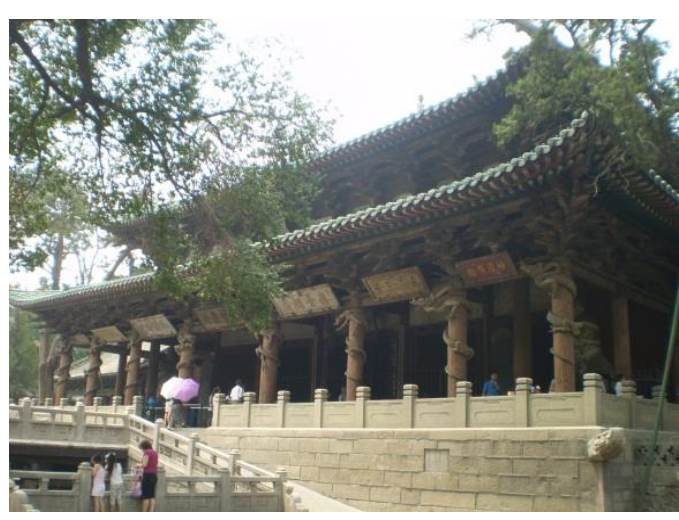

Fig. 1. Shanxi Province Taiyuan Jinci goddess hall.

Jinci goddess hall as the main building of Jinci, sits on the west side of the East and backs to the mountain rock, facing the fish marsh spring, and the hall base is located on the west side of the fish marsh spring. There are seven rooms in the temple of the goddess hall, 19 meters high, six deep, the eaves resting on the top of the mountain, the back of the cloister and the front porch to the depth of two, giving people a feeling of great spacious hall. This is the earliest example of the existing buildings in China.

The lower part of jinci goddess hall has a tall platform, the arch support building and the foundation moisture-proof function, the platform is surrounded by stone column railing. The platform is made of gray stone paving, the floor of the corridor around the building is also light gray stone paving. All the colors are consistent. The roof of the building is the top of the roof. The roof is paved with brilliant glazed tiles. The color of the tile is mainly yellow green, the middle of the roof is yellow colored glaze, and the roof is paved with green glazed tiles. The roof is clearly defined, and the color of roof is carved vividly and brightly. There are very detailed relief patterns on the ridges, which are very delicate between yellow and green in "Fig 2". 


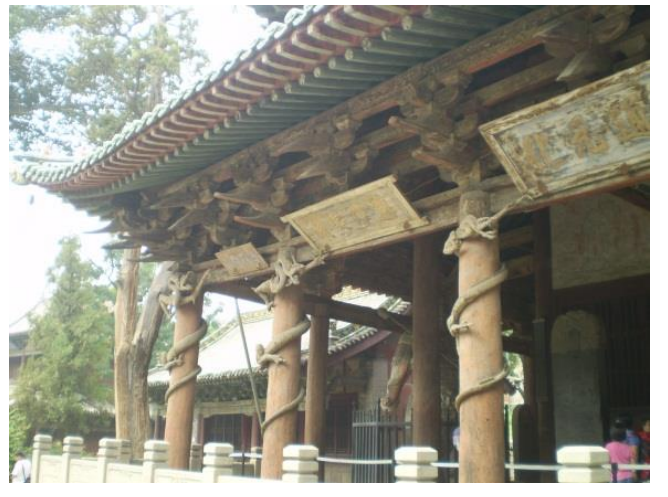

Fig. 2. Shanxi province taiyuan Jinci goddess hall façade.

The lower part of the eaves is made up of red and green strips, so that the green red and green intervals are formed. The color contrast is intense, and cold and warm contrast. The wooden structures, such as the arch beam frame under the eaves, are decorated with color paintings. According to the "Yin Zao Fa Shi" in the provisions of the painting, the painting frame brackets goddess hall belongs to the "nian yu zhuang". It is only inferior to the multicolored decoration. It belongs to the top color painting with the multicolored decoration. Color painting is based on white as the background color, and it is used to superimposed draw the color with green. The color is elegant and the patterns are mostly plant patterns. Due to perennial weathering and erosion, some color paintings have fallen off, revealing vermilion.

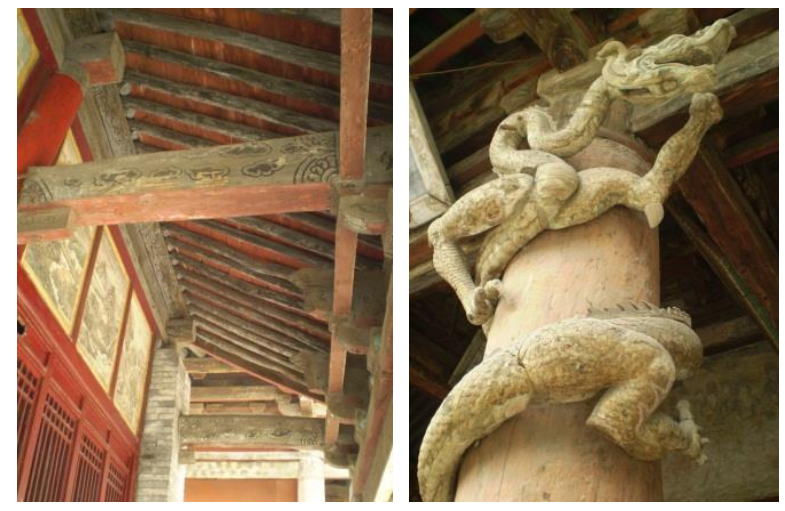

Fig. 3. Color painting and wood carving.

The column of the building is painted with Chinese red, and the most distinctive is the wooden dragon carved on the eight pillars of the front of the palace. It is the oldest wooden carving dragon relics in China. Because of its long history, the color of dragon wood carving has almost faded away. However, we can vaguely recognize that the colors of color drawing are yellow, green, red and so on. The eight dragons each hold a pole very realistic. It can be seen that the sculptures were very well done at that time in "Fig. 3".

The front gate, door frame, window and window frame of the main hall are all painted with Chinese red. The walls and side facades under the windows and the walls of the North facade are mostly painted with Chinese red. In addition to the facade, the walls of the three facades, which are about one meter apart from the ground, are decorated with small rectangular masonry, and the height above the masonry is uniform used Chinese red.

The walls above the facade, the doorframe and the window frame are painted in white, and decorated with frescoes. Most of the mural frescoes are painted on white, and then drew. The themes of frescoes are character story paintings, which are mainly colored by lines and color rendering. Color is not bright, but fresh and elegant, and its colors are mainly red, green, yellow, brownness and so on in "Fig. 4".

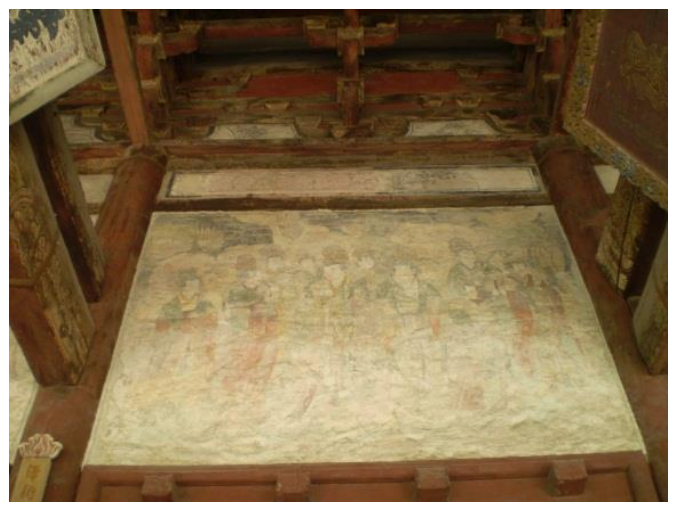

Fig. 4. Facade murals.

The front and the right sides of the hall are divided into two tall, clay sculptured door gods. The sculptures are huge, powerful and lifelike. Clay sculpture color is used more widely, mainly using red, green, blue, brown, yellow, and so on. The portrayal of the figures of the sculptures is very vivid, give a person with heavy and true feeling. Even after hundreds of years, the color has faded a lot, but is still vivid in good out of a bandbox in "Fig. 5".
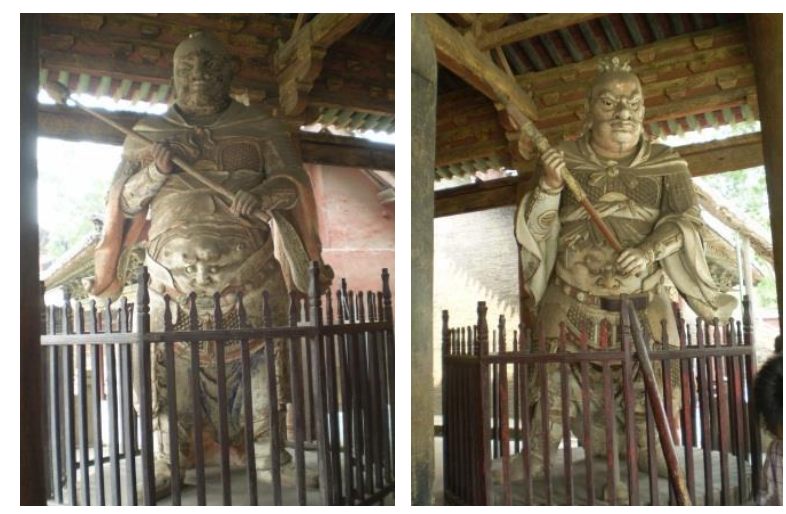

Fig. 5. Front door sculpture.

The interior surface of the hall is paved with deep black stones, and the light gray stone is laid on the floor about half a meter along the edge of the sculpture platform. The indoor wall is about one meter in position with is a red stripe. The walls above red stripe are all painted with white paint. The top surface of the indoor no roof, roof beams of wood components are unified painted red, simple and generous. 
There are forty-three statues in the main hall. These statues are all original objects in Song Dynasty. The arrangement of characters is based on the court system of feudal society, which is the epitome of royal life in Song Dynasty. The colors of the main gods are mainly red, green, yellow, blue and brown. The platform base of the main image of the main image is decorated with glazed bricks. The color uses glaze brick between yellow and green, and the brick surface has flower pattern and other relief. The main patterns are plant stripe, figures and animals. The rest forty-two statues stood on the side of the hall, some of them are plump, beautiful, and rounded. The sculpture colors are Chinese red, dark red, brown, blue, green, brown and so on. It feels like a smart, lifelike form in "Fig. 6".

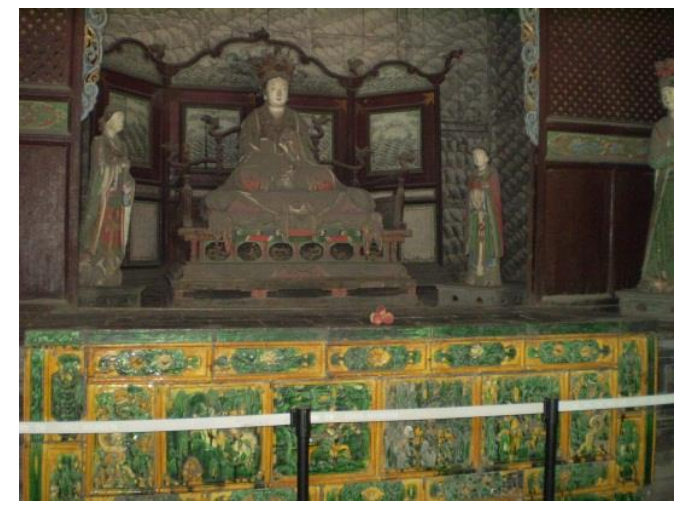

Fig. 6. Interior sculpture.

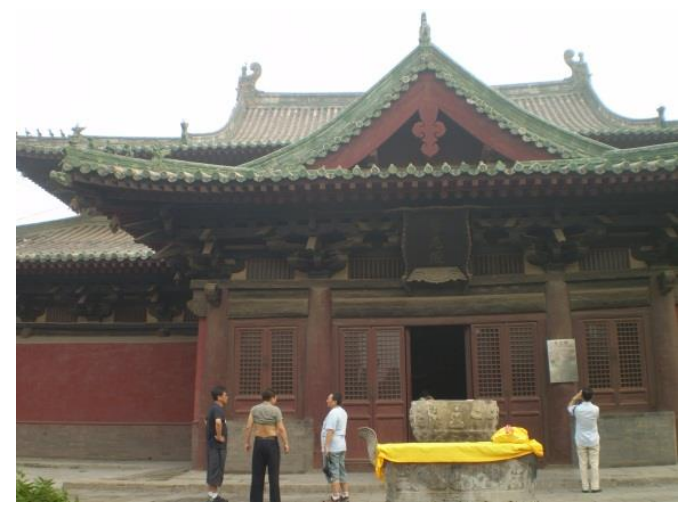

Fig. 7. Hebei Longxing Temple mani Temple.

\section{REMAINS OF THE SONG DYNASTY LONGXING TEMPLE}

Longxing Temple was founded in the Sui kai huang six year (586 AD), song kai bao four years (971 AD). Emperor Taizu of Song ordered to build a bronze statue and built the great mercy Pavilion. In this way, a group of buildings in the Song Dynasty as the main body of the great mercy Pavilion had been built. In this long historical era, Yuan, Ming and Qing dynasties all had been renovated. The main building and the overall layout still maintain the shape and style of the architecture in the Song Dynasty.

Longxing temple face south with the back to the north, plane is rectangular. The whole layout is arranged according to the axis of the north and south. The main buildings are the temple of heavenly king, the temple of Mani, the altar, the pavilion of the transfer wheel, the pavilion of Kangxi's Royal stele, Qian Long's Royal stele, the great compassion Pavilion, and the Amitabha Hall, etc. The entire building area covers an area of about fifty thousand square meters. The main buildings are distributed on the north and south central axis.

The Song Dynasty temple building mani temple in front of the building is one of the main buildings. It was built in four years of emperor Song Renzong's (1025 AD), and the plane of the building was in a cross shape. Wide and deep into the hall for seven, main color of nine double eaves and ridge roof is green. The edge of the roof with green glazed, in the middle area of the roof laying light gray bois.The wooden bars under the roof of the roof are uniformly painted Chinese red, and the windows and doors of the facades were also painted with Chinese red. The four walls below the window frames are all with small rectangular brick and stone face, and the color is light gray.

More special is the white wall around the building is located between the beam and the brackets are provided with a plurality of small panes for lighting. The wooden components such as girder and brackets are painted black, which may be the black paint that is re painted at the later stage of repair. According to the situation of the painted arch in the main hall, we should conclude that in the Song Dynasty, the wooden components outside the building should also be painted. Main shrine hall color of the facade of the main hall is strong and contrasted, from top to bottom. In turn, it is green, red, black and gray in "Fig. 7".

Mani temple building and other wood components were subjected to beam brackets painting. Because of the long history, the color painting is blurred, and the patterns cannot be identified. The main colors used in color painting are red, green, blue and so on. According to the existing color, we can imagine that the color paintings at that time must be patterns, beautiful and colorful. The column used brown planting, color deep, and painted between girders and arch, highlight the gorgeous painting.

Inside the walls drawn by Buddhist story paintings of the Ming Dynasty Chenghua years. The frescoes are huge, and there are about more than 300 square meters of frescoes. Frescoes are rich in color, careful in conception, smooth in lines, and vivid in character. The depiction of characters in murals is not the more ancient Buddhist figures, but rather secularization. The Buddha in the murals is closer to the real characters. The costumes are graceful and the movements are natural. The color of frescoes is mainly based on cool colors, and lots of green blue are used. In addition, Chinese red, brown, yellow and so on are very colorful. The description of characters is mainly based on black lines. Others also use gold lines to express in "Fig. 8".

Three statues of Buddha were placed inside, and Shakya Muni, who was in the middle, was his disciples, Kuangye and Anan. These three Buddha statues are all sculptures in the Song Dynasty. These three Buddha statues are all golden. The Buddha's background and Buddha's stage are decorated with blue, dark red and yellow. It has geometric art and plant patterns, and its colors are bright, intense, highly saturated 
and highly decorative. Behind this group of sculptures, there is a colorful rockery carved on the wall. The statue of dragons, lions and elephants on the rockery are very realistic.

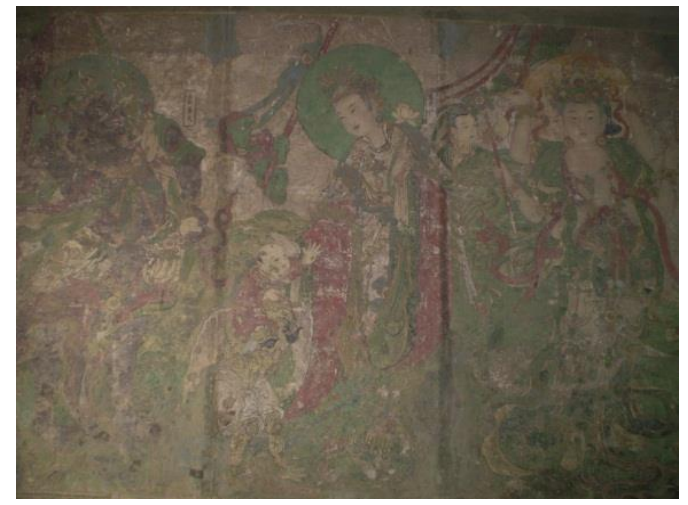

Fig. 8. Mani temple wall murals.

In the middle of the Ming Dynasty for the Ming Dynasty, the Ming Dynasty five colored hanging plastic Guanyin image, the chest arm bare and round, body proportioned moderate, a foot tread lotus, a foot in the rise, hands to caress the knee, a comfortable appearance, quiet face, graceful posture, lifelike. The color uniformity of the rockery is mainly composed of cool colors, blue green, and yellow and orange color saturated and showy. The color of Guanyin is white. The clothes are green, red, brown, yellow and so on, which are strongly contrasted with the cold tones of the background. They play the role of highlighting the main body Guanyin image in "Fig. 9".

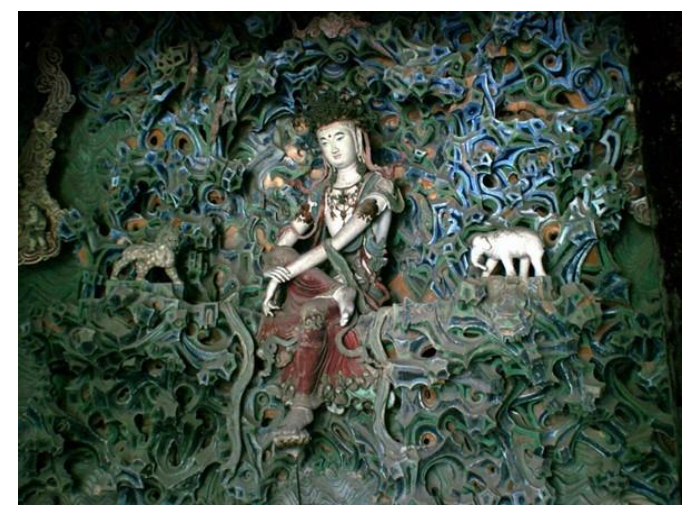

Fig. 9. Mani Temple Buddha.

\section{The InFluence of Color CUlture, AESTHETIC} TASTE AND SOCIAL THOUGHTS ON ARCHITECTURAL COLOR

Most of the battlefields in the Song Dynasty were in the north, and frequent wars in the North seriously hampered the development and progress of economic culture. The economic and cultural center began to move southward from the north to the south.

Because of the southward shift of the economic and cultural center, the concept of social aesthetic culture has changed. From the original northern bold and unconstrained changed to the South meticulous and gentle beauty. The society gradually changed from advocating force to advocating literature. The elegant culture prevailed. The aesthetic culture of the society formed a gentle and elegant style. The transformation of social aesthetic culture has a great influence on the use of architectural style and architectural color. The color of architecture gradually changed from the luxurious and bold in the Tang Dynasty to the gentle elegance in the Song Dynasty.

In addition to the transformation of social aesthetic culture, the rulers of the Song Dynasty advocated the coexistence of three religions at the same time, and established the official ideology represented by neoConfucianism. Neo-Confucianism's theory is still the traditional ethics of Confucianism. In the theory of human nature, he advocates "to go to human desires and to live in nature".

With the development of neo-Confucianism theory, people believe that three cardinal guides and the five constant virtues as specified in the feudal ethical code must be followed. With the influence of neo-Confucianism concept, people pursuit of color from luxuriant Tang Dynasty change to simple and elegant Song Dynasty. Because of the development of neo-Confucianism, the color grade system is also more stringent. The use of architectural color is restricted by the hierarchy system.

\section{CONCLUSION}

The architecture in Song Dynasty had further development and transformation on the basis of the Tang Dynasty. In this period, the concept of color hierarchy was more stringent than that of the previous dynasties, and the color system was more perfect. The color grade system of architecture in Song Dynasty is more clearly classified. The most complete code of architecture in China is "Yin $\mathrm{Zao} \mathrm{Fa}$ Shi" (The Rules of Architecture). The book has clear rules for the use of building colors and so on. It shows that the architectural color of Song Dynasty has a high level of standardization and Stereotyped.

The Song Dynasty architectural color compared with the Tang Dynasty, bright but not strong, more elegant. Gradually from Sui and Tang Dynasties unrestrained freedom, strong change of gorgeous color gentle to elegant and pleasant color style. At the same time, the system of architectural color painting has also become mature and perfect. "Yin Zao Fa Shi", there is a clear stipulation for the use of color painting and the use of colors, and the architectural color painting grade system is also more clear. In addition, with the development of society, building materials technology is developing constantly, making the color more colorful. On the whole, the architectural color of this period is influenced by many factors, forming gorgeous but graceful, rich but elegant features.

\section{REFERENCES}

[1] Wang Xiaoguang, Development of official building if the Chinese traditional colorle, Master thesis,southeast university,2011 
[2] Hu Maosheng, Color composition in traditional architecture, Home Drama, vol. 13, 2017, pp.185

[3] Wang Xiaoguang, The study of architectural color in the pre Qin period of China, Architecture \& Culture, vol. 1, 2017, pp. 95-96.

[4] Cheng Zhiyong, Color features and Inspiration of Chinese traditional architecture, Journal of Nanjing Institute of Technology(Social Science Edition), vol. 1, 2016, pp.39-43. 